\title{
Approach to endoscopic procedures during COVID-19 pandemic - not as expected
}

\author{
Tomasz Ratyński ${ }^{1}$, Arkadiusz Bednarczuk ${ }^{1}$, Grażyna Rydzewska ${ }^{1,2}$ \\ ${ }^{1}$ Department of Internal Medicine and Gastroenterology with IBD Subdivision, Central Hospital of the Ministry of the Interior \\ and Administration, Warsaw, Poland \\ ${ }^{2}$ Collegium Medicum, Jan Kochanowski University, Kielce, Poland
}

Gastroenterology Rev 2020; 15 (4): 275-278

DOI: https://doi.org/10.5114/pg.2020.101555

Key words: SARS-CoV-2, COVID-19, pneumonia, gastrointestinal endoscopy.

Address for correspondence: Arkadiusz Bednarczuk, Department of Internal Medicine and Gastroenterology with IBD Subdivision, Central Hospital of the Ministry of the Interior and Administration, Warsaw, Poland, phone: +48 501688 233, e-mail: arek@sebe.pl

\begin{abstract}
The SARS-CoV-2 epidemic and ensuing transformation of the Central Clinical Hospital of the Ministry of the Interior and Administration in Warsaw into one of the largest specialist infection disease hospitals in Poland imposed a complete reorganisation of work, including in the endoscopy unit. For the vast majority of hospitalised patients, COVID-19 infection posed an extra burden in addition to already known and treated chronic disorders. Therefore, the work schedule and infrastructure have been rearranged in order to minimise the risk of transmission of infection to the personnel as well as to ensure continuous preparedness to perform all endoscopic procedures in patients infected with or suspected of SARS-CoV-2 infection. Between 16.03.2020 and 20.07.2020 we performed 91 endoscopic procedures involving the upper and lower gastrointestinal tract. The majority of those procedures were performed for urgent indications and as a part of on-call duties. The scope of endoscopic procedures was much broader than initially anticipated at the beginning of the epidemic, indicating the need for a change in the recommendations in that regard. Thanks to the application of appropriate procedures and personal protective equipment (PPE) there were no cases of infection among the employees of the Endoscopy Unit coming in direct contact with patients during the above-mentioned period.
\end{abstract}

\section{Introduction}

The first case of severe interstitial pneumonia due to infection with SARS-CoV-2 in Europe was described in Italy in February 2020. The World Health Organisation (WHO) declared COVID-19 a pandemic as early as March 11, 2020. The first case of the disease in Poland was confirmed on March 4, 2020. School classes were suspended from March 12, 2020 and, according to the regulation of the Minister of Health, a state of epidemic emergency has been in effect since March 20, 2020. During that time, i.e. at the end of March, as many as 74,000 confirmed cases and 7500 deaths were reported on in Italy [1].

By the decision of the government authorities, selected medical centres were transformed into specialist infectious disease hospitals. Our hospital became one of the largest centres of this type on March 16, 2020.

\section{Specialist Infectious Disease Hospital, adaptation, guidelines}

Since the first days of the epidemic, our hospital has undertaken actions toward adaptation of wards, clinics, and laboratories to functioning under new conditions. All hospitalised patients were discharged home or transferred to other hospitals. Visits by family members were strictly prohibited. Communication routes, including elevators, were designated in such a way that clean and dirty pathways would not cross. Accident and Emergency (A\&E) was adapted to admit patients with suspected or confirmed SARS-CoV-2 infection. All departments and labs were fitted with partition walls, forming clean and dirty sluices, which were equipped with disinfectants. Hospital personnel underwent mandatory training, both theoretical and practical. Everyone was trained with regard to proper use as well as techniques of donning and doffing personal protec- 
tive equipment (PPE). Personnel were ordered to wear masks while in hospital.

The Endoscopy Unit at the Department of Internal Diseases and Gastroenterology with Inflammatory Bowel Disease Unit was adapted by separating two treatment rooms dedicated to infected or suspected patients [2]. Only the equipment necessary to perform endoscopy was left there, to ensure more effective disinfection [3]. Other rooms were used to prepare before the procedure and to write reports. Another room was designated to changing into personal protective equipment. Taking into consideration that all hospitalised patients were either COVID-19 suspected or infected, all procedures performer in the lab were considered high-risk [4]. It was assumed that the risk of personnel exposure to aerosols generated by the patient during upper GI tract procedures was elevated. Similarly, the risk of coming in contact with faeces during procedures on the lower GI tract was considered high $[5,6]$. In order to minimise the risk of virus transmission, all procedures were performed with the assistance of the anaesthetic team. Anaesthetists decided about the type of sedation and the need for intubation depending on the patient's condition and indications for the procedure.

\section{General patient and staff safety procedures}

The endoscopic and anaesthetic teams used personal protective equipment according to the donning and doffing procedures presented below [7]. Due to the reports of the greatest proportion of infections oc- curring during doffing PPE, the greatest emphasis was put on the process of undressing, which was repeatedly exercised by each employee before the first procedure (Table I).

On each occasion the endoscopic team comprised two nurses and a doctor inside the lab and one nurse in the clean sluice, needed in order to deliver additional equipment from the storeroom if necessary. Also, the anaesthetic team comprised two anaesthetic nurses and an anaesthetist [8].

Every patient transferred to the endoscopy unit had to wear a surgical mask, which was taken off immediately before the procedure. A new mask was put over their mouth before transfer to the ward. Conscious patients wore gloves at the time of transfer and during the procedure. At the time of the procedure, the patient was covered with an interlining fibric sheet. Afterward, the equipment and surfaces (including communication routes) were disinfected and air in the lab was ozonised [9].

\section{Endoscopic procedures}

While developing an operational strategy for the Endoscopy Unit we followed the guidelines of the Polish Society of Gastroenterology [10], which in turn based its recommendations on the first Chinese and Italian reports from the beginning of the pandemic. They implied that endoscopic procedures in patients infected with or suspected of SARS-CoV-2 infection are relatively rare and mainly include procedures for upper GI bleeding and endoscopic retrograde cholangiopancreatography (ERCP) in cholangitis. To our surprise, the profile of

Table I. Procedure of donning and doffing PPE

\begin{tabular}{|c|c|}
\hline Donning & Doffing \\
\hline 1. Put on FFP3 (N95 or FFP2 or FFP3, as per guidelines) & $\begin{array}{l}\text { 1. Take off the third pair of gloves (if present) and disinfect the } \\
\text { hands }\end{array}$ \\
\hline 2. Put on the cap to cover hair and ears & $\begin{array}{l}\text { 2. Take off the visor and perform initial wiping with tissues soaked } \\
\text { in disinfectant. Place the visor in a cuvette with disinfectant } \\
\text { fluid }\end{array}$ \\
\hline 3. Put on the goggles & $\begin{array}{l}\text { 3. Wipe the coverall hood, upper limbs, and trunk (especially } \\
\text { around the zipper) with disinfectant }\end{array}$ \\
\hline 4. Put on the first pair of gloves & $\begin{array}{l}\text { 4. Move to the dirty sluice, disinfect hands; take off the coverall } \\
\text { suit so that the internal surface of the suit is gradually untucked } \\
\text { and to avoid contact with the external surface of the outfit. } \\
\text { Hand disinfection is necessary after taking off the second pair } \\
\text { of gloves }\end{array}$ \\
\hline $\begin{array}{l}\text { 5. Put on the coverall suit (possibly cutting a hole for the thumb } \\
\text { to prevent the sleeve sliding down) }\end{array}$ & $\begin{array}{l}\text { 5. Take off the goggles followed by the cap, starting from the back. } \\
\text { Perform hand disinfection }\end{array}$ \\
\hline 6. Put on shoe covers or rubber boots & $\begin{array}{l}\text { 6. Move to the clean sluice, disinfect hands, take off the mask, } \\
\text { take off the last pair of gloves, and perform hand disinfection }\end{array}$ \\
\hline 7. Put on a visor & 7. Leave the sluice \\
\hline
\end{tabular}


Table II. List of endoscopic procedures and indications

\begin{tabular}{|c|c|c|c|c|c|c|}
\hline \multirow[t]{2}{*}{ Procedure } & \multirow[t]{2}{*}{ No. } & \multicolumn{5}{|c|}{ Indication } \\
\hline & & Upper GI bleeding & $\begin{array}{c}\text { Suspected } \\
\text { neoplastic disease }\end{array}$ & $\begin{array}{l}\text { Cholangitis, } \\
\text { cholelithiasis }\end{array}$ & $\begin{array}{c}\text { Feeding, PEG/NG } \\
\text { tube }\end{array}$ & $\begin{array}{c}\text { Diagnosis } \\
\text { of dysphagia, } \\
\text { obstruction, other }\end{array}$ \\
\hline Gastroscopy & 64 & $\begin{array}{c}35 \text {, including } \\
\text { bleeding control } 15 \times\end{array}$ & $\begin{array}{l}\text { 5, oesophageal } \\
\text { stenting } 4 \times\end{array}$ & & $10 / 4$ & 10 \\
\hline Colonoscopy & 8 & $\begin{array}{l}\text { 5, Including bleeding } \\
\text { control } 2 \times \\
1 \times \text { bleeding from } \\
\text { haemorrhoids }\end{array}$ & $\begin{array}{c}2, \\
\text { tumour 1× } \\
\text { polyps } 1 \times\end{array}$ & & & 1, C. difficile \\
\hline ERCP & 15 & & $\begin{array}{c}8 \\
\text { Tumour of the hilum } \\
\text { or bile ducts; } \\
8 \times \text { stenting }\end{array}$ & $\begin{array}{c}7 \\
\text { Including } \\
\text { pancreatitis } 2 \times\end{array}$ & & \\
\hline EUS & 4 & & $\begin{array}{l}2 \text { - tumour of the } \\
\text { hilum; bile duct } \\
\text { tumour; }\end{array}$ & 2 & & \\
\hline
\end{tabular}

hospitalised patients imposed broadening the scope of procedures to include colonoscopy and endoultrasonography (EUS) due to much wider indications than initially assumed. Patients hospitalised due to confirmed or suspected COVID-19 infection were often chronically ill, mainly for oncological reasons.

During the pandemic, between March 16, 2020 and July 20, 2020, we performed a total of 91 endoscopic procedures, including 33 patients with a confirmed SARS-CoV-2 infection. The remaining group consisted of 58 patients who either were awaiting the result, their result was questionable, or stayed in the observational ward.

In accordance with the guidelines and internal recommendations, the priority was given to the procedures performed for urgent and life-saving indications. Of all 64 gastroscopies, as many as 35 were performed due to upper Gl bleeding or suspected bleeding. In 15 cases we applied endoscopic methods of bleeding control, such as: adrenaline injections, metal clips, Hemospray, banding of oesophageal varices, and obliteration of gastric varices. Four self-expandable metallic stents (SEMS) were inserted due to oesophageal cancer; 10 people underwent percutaneous endoscopic gastrostomy (PEG) insertion and 4 patients had a Flocare nasogastric tube inserted for permanent or temporary feeding. Ten gastroscopies were performed for diagnostic reasons, such as dysphagia, obstruction, or abdominal pain (Table II).

We performed eight colonoscopies, including five for gastrointestinal bleeding. Clipping was necessary in 2 cases. In 1 patient bleeding was due to grade IV haemorrhoids. Two endoscopies were performed due to suspected colon cancer, which was diagnosed in 1 patient.

The main indications for ERCP included suspected tumour of hepatic hilum, extrahepatic bile ducts, or pancreatic tumour resulting in jaundice. In 8 cases the procedures ended with bile duct stenting. Among the remaining procedures, cholelithiasis was the most prevalent diagnosis, and 2 patients were diagnosed with gallstone pancreatitis.

Endoultrasonography was performed in 4 patients: for suspected cholelithiasis, for the diagnostics of cholestasis, and in patients with suspected bile duct tumour and pancreatic tumour. EUS-guided biopsy was performed in the last case.

The total number of patients treated in our hospital during the epidemic was three times lower than during a corresponding period before the epidemic. Figure 1 shows total numbers of urgent endoscopies and procedures performed as a part of on-call duties during

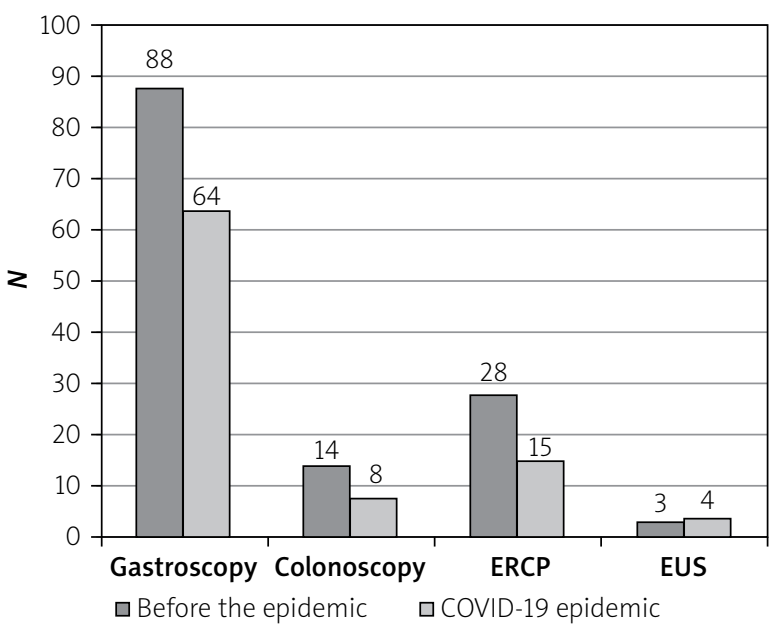

Figure 1. Number of urgent endoscopic procedures during the COVID-19 epidemic compared to the analogous period before COVID-19 
analogous periods before and during the epidemic. It should be noted that, relative to the total number of hospitalised patients before and during the epidemic, the number of urgent upper GI tract endoscopies was statistically higher during the epidemic. This results from a change in the profile of patients admitted to hospital under new conditions - during the epidemic the hospital admitted only acutely ill patients, often with life-threatening conditions, while during periods of normal functioning a large number of patients consisted of elective patients, who generally did not require urgent endoscopic interventions. There were no statistically significant differences with regard to the remaining types of endoscopic interventions relative to the number of hospitalised patients before and during the epidemic.

During the epidemic our department maintained a 24-hour on-call service, and some of the procedures were performed as a part of on-call duty. Some procedures, especially those performed for upper and lower Gl bleeding, required the endoscopy team to move outside the lab. It usually concerned patients in the ITU. Such a team consisted of two nurses and a doctor. One nurse assisted with the procedure, while the other one was in the clean sluice. The procedure generally did not differ from the above-described, aside from disinfecting the equipment in the sluice and transportation along designated routes.

Thanks to the supply of necessary personal protective equipment and training in its use, as well as rigorous adherence to guidelines, all procedures were performed safely. None of the members of the endoscopy team participating actively in treatment was infected with SARS-CoV-2, as confirmed by serological studies or, in the case of questionable results, by negative swabs.

\section{Summary}

The drastic change to the working conditions in Polish hospitals meant also the reorganisation of work in hospital Endoscopic Units. Labs located in hospitals transformed into specialist centres dedicated to the treatment of the most severely ill patients with SARS-CoV-2 assumed particularly important roles. Initial objectives limiting the range of procedures performed in the Endoscopy Unit during the pandemic to life-saving treatments only were challenged by the increased demand posed by patients infected with SARS-CoV-2 as well as burdened with other diseases, mainly oncological. This indicates the need to verify current recommendations regulating management in endoscopic units during the current pandemic. The total number of admissions to our hospital after implementing changes in activity decreased threefold compared to an analo- gous period before the epidemic, indicating that the potential of this hospital was not optimally utilised. The development and following of completely new guidelines, and adaptation of the unit's infrastructure in our hospital, demonstrated that it is possible to provide patients with full endoscopic diagnostics and therapy while maintaining epidemiological safety of the medical personnel.

\section{Conflict of interest}

The authors declare no conflict of interest.

\section{References}

1. Elli L, Rimondi A, Scaramella L, et al. Endoscopy during the COVID-19 outbreak: experience and recommendations from a single center in a high-incidence scenario. Dig Liver Dis 2020; 52: 606-12.

2. LK T, Ang LS, Foong TW, et al. What we do when a COVID-19 patient needs an operation: operating room preparation and guidance. Can J Anaesth 2020; 67: 756-8.

3. Cai J, Sun W, Huang J, et al. Indirect virus transmission in cluster of COVID-19 cases, Wenzhou, China, 2020. Emerg Infect Dis 2020; 26: 1343-5.

4. Xiao F, Tang M, Zheng $X$, et al. Evidence for gastrointestinal infection of SARS-CoV-2 Gastroenterology 2020; 158: 1831-3.

5. Gu J, Han B, Wang J. COVID-19: gastrointestinal manifestations and potential fecal-oral transmission. Gastroenterology 2020; 158: 1518-9.

6. Wu Y, Guo C, Tang L, et al. Prolonged presence of SARS-CoV-2 viral RNA in faecal samples. Lancet Gastroenterol Hepatol 2020; 5: 434-5.

7. WHO. Rational use of personal protective equipment (PPE) for coronavirus disease (COVID-19): interim guidance 2020.

8. Chang D, Xu H, Rebaza A, et al. Protecting health-care workers from subclinical coronavirus infection. Lancet Respir Med 2020; 8: e13.

9. Kampf G, Todt D, Pfaender S, et al. Persistence of coronaviruses on inanimate surfaces and their inactivation with biocidal agents. J Hosp Infect 2020; 104: 246-51.

10. Marek T, Reguła J, Kamiński MF, Rydzewska G. Polish Society of Gastroenterology and gastroenterology national consultant guidellines concerning digestive endoscopy during COVID-19 pandemic. Gastroenterol Klin 2020; 12: 1-6.

Received: 3.11 .2020

Accepted: 9.11 .2020 